\title{
Derecho y Literatura
}

\author{
Por el Dr. LUIS ALBERTO GAZZOLO, \\ Catedrático de la Universidad Católica
}

Los abogados deben estar posesionados de sapiencia. Vale decir, de buen sentido y de una profunda cultura. Sin embargo, la tarea cuotidiana de la defensa, si bien nos hace conocedores cada vez más hondamente el caso de derecho, también se presta a desdorar nuestro estilo, el que insensiblemente va tomando el frío léxico del expediente. La jerga jurídica se posesiona e impera en nuestras expresiones. El abogado que no frecuenta a los autores de la buena Literatura, está muy lejos de poder expresarse como un Larra o de tener la concisión de un Azorin. Por eso creo que los abogados debemos leer a los clásicos, pues de esta manera no sólo conocemos sus mejores pensamientos, sino sus mejores expresiones. $Y$ digo mal. No los debemos sólo leer, sino estudiar, porque las obras de la literatura nos brindan abundante casuística jurídica. Hay quienes sostienen que Derecho y Literatura son mundos opuestos. Creemos nosotros que esto no es verdad, sino que son esferas íntimamente relacionadas.

Femando de Rojas, abogado ilustre e inmortal autor de "La Celestina", escribió su obra ocultóndose, porque no le pareció propio de un jurista hacer comedias, o porque, como dijo en su carta $\alpha$ un su amigo, hubieran pensado que dedicaba a la obra demasiado tiempo en perjuicio de los pleitos y no, como fué, "quince días de unas vacaciones". Lo cierto es que estos quince días lo inmortalizaron en el campo de las letras, al plasmar en su obra un tipo psicológico de tanta vitalidad como la Celestina, obra que ha influído durante más de 50 años en el teatro español.

El primer punto de contacto entre la Literatura $y$ el Derecho se verifica a través del estilo. El estilo y lenguaje de la ley, señala Radbruch, es con frecuencia censurado; al estilo legal se le reprocha pobreza, frialdad, aridez, mientras que el lenguaje forense es pomposo. En realidad, esta diferencia estriba en que el estilo de la ley no puede ser dirigido a los sentimientos, $\alpha$ los afectos, sino que tiene que manifestarse en toda su sencillez y con una precisión casi matemática. En cambio, el lenguaje forense se vuelca, a veces, en sonoros epítetos, como el usado en nuestros Tribunales Correccionales por los defensores, quienes revisten a sus expresiones de toda pompa para aminorar la monstruosidad del delito cometido por el reo que patrocinan. ¡ Cuảnta verdad! encierra el aforismo alemán: "la razón y el buen sentido no necesitan aderezarse con bello ropaje". 
Actualmente el lenguaje de la ley, en la mayor parte de las legislaciones del mundo, rehuye el estilo didáctico. No entra a explicaciones ni. disquisiciones académicas. Esto lo observamos en nuestro vigente Código Civil, en donde las definiciones han sido reducidas al mínimum. Por eso, el abogado de causas civiles debe ser una mezcla de calor y frialdad. Frialdad para plasmar ordenadamente los conceptos generales y calor para darle vida a estos conceptos; pero sobre todo debe ser un fiel intérprete de la ley, ya que muchas veces ésta no es clara y necesita de una fina sensibilidad para ser aplicada en su verdádero sentido: ius vigilantibus scriptum.

No han faltado, sin embargo, quienes afirman que entre Derecho $y$ Literatura existe un abismo insondable, que el abogado "por el hecho de serlo, es una bestia nociva para el arte" $y$ que el hombre de leyes termina por desquiciar las formas de expresión. Así nuestro criollísimo Felipe Pardo y Aliaga, en su renombrado artículo costumbrista "El Paseo de Amancaes" dedica algunos pensamientos a los jueces y abogados, al decir: "Somos jueces y con un Vistos (que no son Vistos, sino oídos, porque quien los ve es el relator) dejamos por puertas a una viuda honrada, y despachamos a un infeliz al otro mundo"........ "Somos abogados, y sembramos la discordia en las familias, y viciamos la lógica y corrompemos el buen gusto y acabamos con el pobre idioma castellano, que, de todos los godos perseguidos, es el que más larga y más encarnizada persecución ha sufrido en nuestras grescas revolucionarias". Indudablemente que Pardo y Aliaga es uno de los partidarios, en nuestro medio, de la tendencia que sostiene que Derecho y Literatura son incompatibles entre sí.

Igual arraigo a esta corriente notamos en la producción satírica de Abelardo Gamarra "El Tunante", quien, con la sal de su ironía, se mofa en muchos de sus artículos de nuestros hombres de leyes, en especial a través de "Juan Pichón', prototipo del estudiante de Derecho sin emoción ni cultura, quien, después de hacer sus dos años de práctica en el estudio del Dr. Juan Manuel García Carabobo y Siete Jeringas, se gradúa de abogado por inercia, redactando, como es de costumbre, para el periódico el sueltecito: "Juramento.- Hoy ha prestado Juramento ante la Excelentísima Corte Suprema, el estudioso y recomendable joven Juan Pichón, uno de los mejores pichones de San Marcos". Y claro está que, mediante el autobombo y el despliegue de fuerzas burdamente deslizadas entre sus amigos del mundo político, Juan Pichón alcanza la Judicatura de la Provincia de Pelogatos.

Estas citas podrían multiplicarse a discreción. Sin embargo, hay literatos que se encuentran bien avenidos con la Jurisprudencia, como juristas y magistrados que incursionan con éxito en el campo de las letras. Tal, por ejemplo, el poeta Hoffmann, que deslizó su existencia entre el mundo de la poesía y el de la jurisprudencia, o el italiano Ugo Betti, que fué escritor y magistrado al mismo tiempo, plasmando con insuperable maestría la vida gris y humilde de la gente modesta. Betti, cuya fama ha traspuesto los límites de Italia, ganó merecido renombre con su comedia: "Escándalo en el Palacio de Justicia" (Scandalo al Palazzo di Giustizia). El título no puede 
ser más llamativo $\mathrm{y}$, en efecto, ha sido una de las obras dramáticas que ha obtenido más éxito, en lo que va de los años corridos entre 1948-1950.

No menos interesante es, la figura del abogado literato. Abogado en ejercicio fué en España Feliú y Codina, el ilustre autor de "La Dolores"; Díaz Cobeña, Alberto Valera Martin, José María Pemán y Juan Valera, que cultivaron y cultivan con fortuna la poesía; la novela y la dramática. Literato fué con su claridad y singular gracejo don Angel Osorio, autor de los amenísimos libros "El Alma de la Toga" Y "Mujeres" (Libro que no deben leer las mujeres), en donde refleja algunas de las figuras femeninas que acudieron a su bufete en pos de consulta. Abogado fué otrora en nuestro país, don Pedro de Peralta Barnuevo, autor de "Lima Fundada" y de "España Vindicada". Peralta aplicó y manejó con desembarazo los textos clásicos. Abogados fueron en días más cercanos a nosotros, esos portentos de cultura humanística: Don José de la Riva Agüero y Don Manuel Augusto Olaechea. El uno con el aticismo de su pluma, que, con igual virtud y esmero, trató asuntos históricos, ensayos literarios y comentarios a nuestro Código Civil. El otro, con una tersa concisión de estilo y un notable talento dialéctico que lo llevó a figurar como extraordinario orador forense. Abogado es Enrique López Albújar, autor de "Matalaché", quien ha repartido su tiempo enire los amarillentos folios de expedientes y sus vigorosos esquemas peruanos, que penetran profundamente tanto en la realidad y psicología indígena como en la del mulato y zambo. Abogado es Víctor Andrés Belaúnde, a quien podemos llamar por antonomasia "defensor del Perú" y que militara en la brillante generación novecentista, que ha dado fructífera obra literaria.

El segundo punto de contacto.

Hay un estrato en que tanto el Derecho como la Literatura hunden sus raíces. Este campo es el "Hecho". No puede existir Literatura sin hechcs, vale decir, sin acontecimientos, como tampoco puede vivir lozanamente el derecho sin el hecho. Toda la casuística jurídica es hecho. Tampoco germina la literatura sin esta savia. De allí, pues, que el Derecho y la Literatura se hermanen a través del acontecer humano y jurídico.

a) El Derecho como tema de la Literatura.-No son pocas las obras que toman como asunto el Derecho o todo lo que esté íntimamente ligado a esta disciplina. Gustavo Flaubert era conocido apenas por un grupo de amigos, hasta que escribió su novela "Madame Bovary", basada en el caso de Delamare, tan comentado en los diarios y estrados judiciales parisinos. Igualmente, el caso Dreyfus ha sido tocado con maestría dentro del ambiente literario. Fedor Dostojewski se encuentra, quizás, entre los primeros novelistas que han atisbado con certero enfoque el campo del derecho Penitenciario y del Derecho Pena!; muestra de ello con sus obras: "El sepulcro de los vivos", "Crimen y Castigo" y "Los Hermanos Karamazov". Análisis psicológicos de grandes crímenes encontramos en las obras literarias: "El Criminal en venganza de su honor", del gran Schiller; en la novela "FI Hostelero del Sol", de Hermann Kurz, y en la clásica obra de Feuerbach: "Protocolos de Crímenes célebres".

Gran parte de la fuerte y concisa prosa de Enrique López Albújar es 
reflejo de los pintorescos y míseros personajes que pasaron por su Despacho de Juez, en especial los consignados en "Cuentos Andinos", "Los: caballeros del Delito" y "Nuevos Cuentos Andinos"; entre los que cabe resaltar: "Una posesión judicial" y "El Blanco".

En "El Blanco", Enrique López Albújar nos pinta a Riverita, el abogado limeño cuya plancha soportó el agravio de las miradas indiferentes de los transeúntes, $y$ "las oxidaciones de la intemperie sobre los barrotes de una ventana de reja, a media cuadra del Palacio de Justicia". Riverita cnte la indiferencia de la gente de papel sellado, optó por una'Subprefectura de Abancay. En la provincia se encuentra con un antiguo condiscípulo de estudios universitarios, Diego Montes, quien por propia boca dice que dejó el "Derecho" por aburrimiento. "Para todo el derecho" - dice- "¿Que usted quiere un pedazo de tierra? Derecho. ¿Que usted se quiere casar? Derecho. ¿Que se le muere a usted su padre? Derecho. ¿Que le dan a uno una trompada y la devuelve con un tiro? Derecho...... ¡Qué ricos tipos esos maestros de San Carlos! ¡Ya quisiera verlos por acó para que digan de qué les sirve su derecho! Y cuando Riverita le aclara que el derecho sirve para el caso de que una persona lo despoje de lo suyo, Montes interrumpe: “¿Despojarme a mí? ¡Caracho! ¿A Diego Montes? Como que no sabes tú ciue todos los artículos del Código Civil y del Código Penal los tengo reducidos a cincuenta carabinas con su respectiva dotación de tiros. ¿Qué mejor derecho para defender por acá nuestro derecho que una buena carabina y un corazón resuelto y firme?", Más adelante reconoce, sin embargo, que lo único realmente cierto que decían "los profesorcitos teóricos de Scn Marcos" es que "el derecho de cada cual termina donde empieza el cjeno", aunque también alló en Lima, cuando le ponen la puntería a la propiedad "te la quitan, ya con el pretexto de utilidad pública, ya porque a cualquier señorón de esos se le ha ocurrido ensanchar su dominio. $Y$ te la quitan con papel sellado, que es lo peor". Montes retrata, pues, con toda nitidez el concepto que se tiene en muchos de nuestros pueblos acerca del derecho.

El tema de un gran sector de nuestra Literatura es la injusticia. Ultimamente, la novela "Taita Yoveraqué", de Francisco Vegas Seminario, ganadora del premio creado por los editores Mejía Baca y P. L. Villamueva, toca este punto. El nudo de la obra va desatando con viva animación, los amargos momentos del abusivo despojo que sufre el anciano Taita Yoveraqué por parte del hacendado Eustaquio Escalona. Es el eterno drama de nuestra serranía. La novela a través de sus páginas esboza con todo realismo figuras de maleantes, autoridades y tinterillos. Algunos cuentos de Ciro Alegría y su novela "El mundo es ancho $\mathrm{y}$ ajeno" han descrito con original expresión también este tema. La novela síntesis "Panorama hacia el alba", de José Ferrando, ganadora del concurso Latinoamericano, describe, en cambio, la huída de la justicia, personificada en Navas, que mata en el Callao y ante la amenaza del encierro en nuestra cárcel, huye atravesando Costa, Sierra y Montaña.

Don Ricardo Palma en sus Tradiciones Peruanas: "Dimas de la Tijereta", "Un litigio Original", "Entre si juro o no juro", nos recuerda algunos 
casos con su inimitäble gracia socarrona, deslizando dardos y dichos contra la Justicia y el procedimiento de la época, tales como: "El hombre propone, el juez dispone y el escribano lo descompone", y cuando habla de Son Ivo, patrón de los abogados, afirma que llegado el momento de canonizorlo, el pueblo protestó con esta antífona:

"¿Advocatus et sanctus?

Res miranda populo!"

Pero a quienes más acremente trata el "Bibliotecario mendigo" es a las escribanos, a los que llama con frecuencia cartularios, consignando a través de sus páginas redondillas como estas:

"El signo del escribano,

dice un astrólogo inglés,

que el signo de Cóncer es,

pues ccme a todo cristiono"

"Un escribano y un gato

en un pozo se cayeron:

corno los dos tenían uñas

por la pared se subieron".

Sin embargo, en las expresiones de Palma hay malicia, pero no veneno; en cambio, la Literatura popular alemana al soslayar el tópico de la Justicia, emplea siempre términos que pasan de la sátira a la ofensa, tal como la tremenda advertencia que consigna una edición oficial del Código Civil antiguo de Sajonia y que reza:

"Mucho se roba por tierra y por mar,

Pero los jueces nunca dejan de robar".

b) El Derecho en la Dramática.-El género literario que mós motivos ha tomado del Derecho es la dramática, quizás porque la esencia de la tragedia es siempre una antinomia insoluble, $Y$ el Derecho descansa sobre antítesis y antinomias. Los conflictos del drama giran en torno a las colisiones entre el Derecho y la personalidad individual.

Un drama con visos marcadamente jurídicos es "El Mercader de Venecia", de Shakespeare; sobre todo en la escena culminante del juicio $y$ de la interpretación del contrato. Shylock, un judío usurero, da en préstamo una suma de dinero al mercader Antonio, recordándole las viejas injurias sufridas:

"Señor Antonio: a veces me increpasteis por mi manera de prestar dinero. Soportelo encogiéndome de hombros que el sufrir, de mi raza es distintivo. 
Y le propone un pacto absurdo que es el eje de la intriga. Le prestarớ el dinero sin inf̄erés alguno:

"Mas si en el día no pagáis la suma que convengamos, ha de ser la pena de vuestras blancas carnes una libra que del sitio que a mí se me antojare he de poder cortar de vuestro cuerpo".

Antonio firma para ayudar a Basanio, diciéndole a éste: No temas, confía que mis buques vendrán mucho antes que ese día. Pero transcurre el tiempo, el plazo se vence y los buques no llegan.

Shylock acude a la Justicia, entabla la demanda y el juicio sigue por sus trómites hasta la sentencia; pero al momento de ejecutarla, el Juez le advierte que la escritura no le da derecho ni a una sola partícula de sangre:

"La carne toma. Mas si acaso viertes cuando la cortes, de cristiana sangre tan siquiera una gota, confiscadas tus tierras quedarón para Venecia".

El judío, acosado por todos, llega a verse al borde del suicidio.

Jhering fué uno de los primeros juristas que protestaron contra el hecho de que Shakespeare sea injusto con Shylock, mediante una tergiversa. ción del Derecho al aplicar literalmente las palabras del contrato. Para Jhering, pues, Shylock es víctima de una injusticia.

Lleva también Shakespeare a las tablas una de las más famosas creaciones de la literatura universal: "Otelo", cuyo personaje central encarna la pasión de los celos que desembocan en el uxoricidio. El moro veneciano es confiado, crédulo y optimista por naturaleza, pero la nefasta pasión prende en su alma, merced a las diabólicas maquinaciones de Yago. Decide entonces matar a Desdémona, no sin antes exclamar:

¡Oh, mujer perjura! tú petrificas mi corazón, $\mathrm{Y}$ me obligas a que llame, lo que voy a hacer, un crimen, lo que es para mí un sacrificio. cho literatura.

El Otelo shakespeariano representa, pues, el homicidio pasional he-

No menos interesante es el problema de delincuencia multitudinaria enfocado a la perfección en Fuenteovejuna. Pertenece "Fuenteovejuna" al grupo de las obras dramáticas de Lope de Vega, en donde afronta el problema político y social de España de fines de la Edad Media, de la lucha del pueblo contra la aristocracia, a la cual la Monarquía en un acto de justicia dió razón al pueblo para tratar de reducir el descaro y la creciente agresividad de la nobleza.

Su línea argumental es sencillísima. Un Comendador somete al pueblo de Fuenteovejuna $a$ toda clase de atropellos $\mathrm{y}$ vejaciones porque tiene 
los resortes del poder. Pero viene el momento de la reacción y la rebelión estalla clamorosa $\theta$ incontenible, acabando el pueblo con el Comendador y sus secuaces, mientras un personaje juicioso deja escapar esta sentencia:

"Cuando se alzan los pueblos y resuelven nunca sin sangre $\mathrm{y}$ sin esperanza vuelven......"

La Monarquía quiso saber lo que pasó en Fuenteovejuna y cuando el Rey lleva a juicio al pueblo entero para descubrir a los culpables, éstos, dándose cuenta de las dificultades en que ha de ponerlos la Justicia, oyen de alguien esta regla salvadora:

\section{"Concertaos todos a una \\ en lo que habéis de decir. \\ Mi consejo es el morir \\ diciendo ¡Fuenteovejuna!"}

$Y$ así se hace. Viejos, mujeres, niños, al ser interrogados ¿Quién mató al Comendador? Responden: ¡Fuenteovejuna, señor!

El Juez confiesa su fracaso y el Monarca, magnánimo y justo, reca nociendo que es grave el delito cometido, perdona a Fuenieovejuna. Pero en este drama de las masas, como bien observa Quintano Repollés, la absolución del Rey nace, no tanto de una convicción, sino de una imposibilidad insuperable de prueba. Por lo demás, en aquella época estaba en boga la obra del conspicuo penalista castellano Fray Alfonso de Castro: "De Potestate legis penalis", en donde sostiene "que la muchedumbre debe ser perdonada cuando se somete $\mathrm{y}$ castigada cuando no quiere reconocer su culpa".

En la dramótica contemporánea italiana dos son los representantes que han echado mano al Derecho como base de sus obras: Ugo Betti y Diego Fabbri. Betti es autor de treinta obras teatrales, entre ellas "La Padrona", "Marito e moglie" (Marido y mujer), "Delitto all'Isola delle capre" (Delito en la Isla de las cabras) y "Scandalo al Palazzo di Giustizia", en donde toca las más abiertas llagas sociales y lacras de la injusticia; pero siempre como esperando escuchar un límpido canto a fin de que la reacción se torne en piedad; $y$, en efecto, cuando Betti se nos presenta más despiadado, sus obras se filtran de justicia y concluyen humanamente en un entendimiento fraternal. Se ha dicho, por eso, que la fama de comediógrafo de Betti ha sido sostenida por su toga. Hay mucho de verdad en esta ofirmación, pues Betti nunca dejó de ser magistrado, transportando el sentimiento de justicia fundamental y profesional a su obra.

Betti alcanzó el mớs sonado éxito con "Corrupción en el Palacio de Justicia", considerado como el más fuerte drama puesto en escena en esta post-guerra. La acción se desenvuelve en un país, que no nombra el autor; pero en el cual algunos pueden reconocer el propio. Entre Ias vastas, macizas y polvorientas salas del Palacio, donde hombres oficialmente venerandos por edad $y$ experiencia, se sientan $\alpha$ juzgar a otros hombres $y$ sus destinos...... Ninguno ignora que la corrupción que serpentea en la ciudad, 
se ha insinuado también entre los jueces; que éstos están tan carcomidos como los otros que vegetan en la urbe. $Y$ a este Palacio inmenso, un verdadero laberinto, vienen hasta extranjeros a admirarlo...... pero no se respira en él un buen olor, debe haber algo que no marcha bien, el ambiente. es pútrido..... hay hedor de cadáver. $Y$, en efecto, el inquisidor, que en homenaje a la opinión pública ha sido enviado al lugar para descubrir los móviles de ciertos hechos delictuosos ocurridos en el Palacio, advierte prontamenie el mefítico clima, alguno ha envenenado el aire convirtiéndolo en irrespirable.

El drama está saturado de un impreciso juego de sospechas. Todos: estón íntimamente temerosos, todos exteriormente descarados, todos mós o menos tarados. Sólo Elena, la adolescente hija del más viejo de los vocales, cree y venera la rectitud de su padre, que es el Presidente de la Corte. Pero, de improviso, Cust, un solapado y envidioso colega de su padre, le revela la indignidad paterna, rompiendo con aquel bello sueño de ilusiones que tejen los hijos en lo que concierne a sus mayores; y entonces la frágil adolescente, abatida y desilusionada por el monstruoso coloquio, na puede resistir al derrumbamiento de sus sueños y se mata precipitándose: en la obscura trompa de un ascensor del Palacio.

Al lado del suicidio de la inocente fluye en todo el ambiente dramá. tico $\mathrm{y}$, sobre todo, bajo las venerandas canas de los magistrados, las mús. abyectas intrigas para alcanzar la Presidencia de la Corte, las más inmundas calumnias e imposturas para desprestigiar al buen Juez Vanon, los razonamientos torcidos y malignos que hacen esclavo al hombre y no dejan dormir a los jueces, los arañazos a la conciencia que dejan heridas que no. cierran; en fin, todo un mundo confuso entre un cementerio de expedientes que encierron en sus folios sudores, dinero y suspiros.

La catarsis del drama está en el milagro que se opera por la sangre derromada por la inocente y al último momento por la confesión hecha por uno de los vocales acusados que está a punto de morir, y así Cust, que ha llegado a la cumbre de su carrera judicial por medio de la intriga y de Ia impostura, decide acusarse. La tragedia es lóbrega; sería insostenible si no terminara con ese afón o ansia de necesaria purificación. $Y$ el autor así lo manifiesta a través de su formidable expresión y estilo, con palabras de una vehemencia que rayan en lo horroroso, sobre todo en el diálogo. entre la pureza de la adolescencia y la protervia de su destructor; pero en el fondo blandiendo siempre el concepto de "la necesidad de creer".

De observación atenta, fácil ironía y ágil espíritu, Betti ha sido lisonjeramente decorado con el apelativo de: "continuador de la obra de Pirandello".

El 2 de Marzo de 1955, en el Piccolo Teatro de Milán, se estrenó "Processo a Gesú" (Proceso a Jesús), de Diego Fabbri. La obra tuvo un caluroso éxito y con ella Fabbri afronta un argumento arduo y complejo. Toda la historia de Cristo pasa en el drama en un cuenta-gotas, con una honda preparación histórica, filosófica y procesal; pero siempre alimentada por un inienso fervor, por un ansia de verdad que hace viva la argumentoción pleiórica de calor humano. 
El drama en dos tiempos (o actos) se desarrolla en un clima netamente procesal. Cuando los espectadores ingresan al teatro, el telón está levantado y el escenario tiene todas las características de una fría y escalofriante Sala de Justicia. A los lados y en los palcos de la primera fila se encuentran manifiestos como estos: "Esta noche el público está invitado a participar en el Proceso a Iesús". "El ingreso es libre". De las puertas laterales entran diez o doce personas que se sientan a los lados. En seguida ingresan los Jueces, entre ellos Elías, acompañado de su esposa Rebeca y de sus hijos Sara y David. En suma, la escena se prepara para la revisión del proceso de Jesús; pero los Jueces serón esta vez los judíos de nuestros días.

A la audiencia acuden, amén de los espectadores que intervienen en el debate cual corifeos, un tropel de testigos; entre ellos: María de Nazareth, María Magdalena, José, Pedro, Juan, Tomás, Judas, Caifás y Pilaias. Flota, pues, a través de toda la obra una atmósfera de gravedad. ¿Y cuál es el delito por el que se acusa a Jesús de Nczareth? Se le señala como cabeza de proceso porque con "sus magias sedujo y desvió al pueblo de Israel". El Fiscal advierte que el debate debe versar acerca de estos dos hechos:

lo-Que Jesús se proclamó el Mesías de Israel; y

2 - - Que, consecuentemente, desarrolló un conjunto de actividades soliviantadoras, tanto en el campo religioso, como en el de la vida pública. Sostiene, además, que el debate es eminentemente jurídico y que la discusión debe enmarcarse dentro de este orden. El primer testigo que se presenta a prestar declaración es Caifás, quien afirma que Cristo es un seductor $y$, cuando el Fiscal le pregunta iqué cosa quiere decir con el término seductor? Caifás responde: "Seductor es el hombre que arrastra consigo. Jesús tenía el poder de arrastrar a la gente y cualquier cosa que dijese era creída. No tenía necesidad de convencer, porque encantaba".

Más adelante se pone sobre el tapete la discusión acerca de quién condenó a Jesús. Caifós afirma que, si Pilatos hubiese defendido a Jesús con todo la fuerza que la ley le daba, no hubiese sido crucificrdo, porque si es verdad que Caifás por su cuenta lo condenó, el poder para ejecutar la pena estaba sólo en manos de Pilatos......... Pero, ¿q̣uién era Pilatos? Formalmente un Juez que debía aplicar la ley: pero sustanciolmente un juez político que fué arrastrado por otras consideraciones en la interpretación de Ia ley. Hay que pensar ¿qué podía representar un Mesías hebreo para un político romano? Para Pilatos, Jesús no tenía la culpa $\mathrm{Y}$, sin embargo, la ciudad estaba agitada por su causa, $y$ cuando se persuade de que el profeta se ha quedado solo. que su absolución habría irritado, no solamente a los sacerdotes, sino también al pueblo y quizós si a sus superiores de Roma, cede ante las palabras de Caifás: "Hay que sacrificar a este hombre para la salvación de Israel. Es mejor que uno pague por todos".

Y vuelve, así, a escena la revisión de un proceso que seró siempre el más grande de la Historia, para terminar con las palabras del principal protagonista Elías, que hace el papel de Juez: "Debo proclamar que no sé todavía si Jesús de Nazcreth ha sido verdaderamente aquel Mesías que nos. 
otros esperábamos...... No lo sé..... pero es cierto que El, El solo, alimenta y sostiene desde aquel día todas las esperanzas del mundo! Y yo lo proclamo inocente...... Y mártir..... Y guía". Con estas bellas y sentidas palabras se pone término a esta revisión del proceso a Jesús, hecha en nuestras días por una familia judia.

Este argumento, delicado y sensible, ha consagrado a Diego Fabbri como uno de los más altos exponentes del actual teatro italiano y ha suscitado cálidos debates en el campo jurídico.

Con Jesús se cometió la más grande de las injusticias, como es la de ultrajar la autoridad de Dios, y este ultraje se ha hecho carne en el remordimiento. Los juristas, por su parte, tratan de estudiar esta tajante injusticia. Son varias las obras que han contribuído a descifrar el problema, tales como: "Una provincia pretoriana en los comienzos del Imperio Romano", del renombrado profesor de Historia de Derecho: Regnault, y la ponencia presentada por Jean Imbert al Congreso de Derecho Canónico de 1947 intitulada: "Un punto de Derecho: ¿Es Pilatos quien condenó a Nuestro Señor Jesucristo?". Igualmente, el Consejero Dr. C. Laplatte, Vocal de la Corte de Apelaciones de Colmar, ha publicado recientemente a este respecto, en la revista "Ecclesia", de Porís, un interesantísimo artículo: "El Proceso de Jesús visto por los juristas". El tópico es esencialmente procesal, es cuestión de jurisdicción o de competencia entre las autoridades judías y romanas. Para unos, Jesús fué condenado a muerte por Pilatos; otros, en cambio, sostienen que el drama de la Pasión fué preparado y urdido por el Sanhedrín, asamblea jurídica judía.

c) El Derecho Penal y la Criminología en la Literatura.-Existe también una gran afinidad entre la Literatura, el Derecho Penal y la Criminología. Sin aceptar, desde luego, la afirmación de Tomás de Quincey, quien osó considerar el asesinato como una de las bellas artes, es indudable que, ccmo bien afirma Quintano Ripollés: "la obra de arte $Y$ el "Delito" son creaciones de una minoría de humanos" $y$ es que, en el fondo, el artista es un "eterno insatisfecho" que trata de escapar de la realidad circundante. Algo de esto hay también en el delincuente, el que se evade de su mundo tomando la senda del crimen. Son muchas las obras literarias que han utilizado el crimen como fuente de inspiración estética, asi Dostoyewslii diagnosticó con toda precisión los más turbios sindromes de la epilepsia y la esciuizofrenia, anticipándose a la psiquiatría maderna y sus apreciaciones al respecto, siguen teniendo la más absoluta vigencia. Tal es el caso del personaje central de "Crimen y Castigo", Raskolnïkov, quien siente un absoluto desprecio hacia los valores corrientes de moralidad media $\mathrm{y}$ burguesa, que interpreta como una degenerada debilidad. Pues bien, Raskolnikov, para probar a sí mismo su "heroísmo" personal, su sangre fría, azesina y roba a una vieja prestamista, planeando y ejecutando su crimen con toda minuciosidad. Pero, su mayor sorpresa la vive después del asesinato, al no hallarse tan sereno como él se había imaginado y sufre gran desilusión al comprobar que no es el "superhombre" que se jactaba ser, apoderándose de su persona un extraño complejo de inferioridad. 
Sienáhal, con "El Rojo y el Negro", obra que ha sido tildada como el poema de la envidia, crea en Julión Sorel un protagonista que siente en carne propia el complejo de minosvalía: pero no se da por vencido y de su propia debilidad e impotencia, hace surgir un ingente caudal capaz de cambiar el mundo. Se dice que el filósofo Nietzsche sintió profunda admiración por Sthendal y es que, en el fondo, los dos desconocieron el valor del Derecho Natural, pues su "único Derecho fué la fuerza". Este Julián Sorel, especie de Bonaparte de guardarropía, que hizo de "El Memorial de Santa Elena" su único Evañgelio, es un intoxicado de la leyenda de Napoleón y el paradigma del "lóco moral".

El genio de Cervantes compendió a travẻs de su Quijote y Sancho a los biotipos del asténico y pícnico con no menos maestría que el mismo Kretschmer; e igualmente describió al paranoico en toda su realidad en su "Licenciado Vidriera", anticipándose así en muchos años a la tipología Kretschmeriana $\mathrm{y}$ de Pende. El austero Jovellanos no pudo escapar de ser influenciado por las últimas ideas del marqués de Beccaria, llevando a escena su fainoso "Delincuente honrado". Interescinte es, a este respecto, el conocido estudio del maestro de la criminología moderna, Enrico Ferri titulado: "Los Criminalés en la Literatura".

El refinamiento que deja sentir la Literatura de fines del siglo, al descender a lo más abyecto de las pasiones humanas tiene como fieles exponentes a Oscar Wilde y Gabriel D'Ännunzio. En efecto, "El retrato de Dorian Grey" es un certero estudio del remordimiento de un osesino refinado y esteta, $y$ "El Inocente", de D'Ánnunzio, es la histcria de un filicida que pone fin a los días de su tiemo hijito exponiéndolo al frío de una cruda noche de invierno.

Abundan, también, en la Literatura universal creaciones de delincuentes fanáticos y anarquistas. Sin duda nadie como Pío Baroja ha captado con mayor verosimilitud la extraña complejidad de los anarquistas de raza. P'́o Baroja sintió siempre una gran simpatía por el vagabundismo $Y$ los bajos fondos, llegando en su juventud a convivir con muchos de ellos. Esta es quizás la razón por la que Madariaga lo califica de "sentimental vergonzonte". Para muestra basta mencionar su "Dama errante" Y "El Cabo de las tormentas".

El estudio científico de la masa, en lo psicológico y en lo criminal fué iniciado por los penalistas italianos Pugliese $y$ Sighele con sus obras: "Del Dolitto Collettivo" y "Folla delinquente", respectivamente. Pero la delincuencia multitudinaria se esboza ya en la sublevación milanesa de "Los Novios" (I promessi Sposi) de Alessandro Manzoni, en los desmanes populares de "La Horda" y "La Bodega", de Blasco Ibáñez y en la huelga de "Germinal", de Zola, para completarse con el castizo trozo literario de "Los Episodios Nacionales", de Pérez Galdós, con su inimitable vieja arpía la Maricadalso.

En muchas de las obras de Andrés Gide, el novelista toma como eje de su obra el crimen, así "Les souvenirs de la Cour d'Assises" es sotemadamente un verdadero texto de Derecho Pencl 
d) La didáctica jurídica.-En el género jurídico, cumple la Literatura unce función orientadora y objetiva, sobre todo en la iniciación de los estudios jurídicos. A este respecto, cabe recordar el libro del Dr. Edgar Bodenheimer, tiiulado "Teoría del Derecho", valiosísima obra para todo estudiante de jurisprudencia. En sus páginas, el autor, al explicar las relaciones de Poder y las de Derecho, echa mano a la clásica novela de Daniel Defoe, "Vidc. I Aventuras de Robinson Crusoe" y, con una meridiana claridad, esboza dos ejemplos para establecer los tipos posibles de relaciones entre los hombres. Así la relación entre Robinson y el joven Viernes, a quien salvó de ser devorado por una horda de caníbales, es una relación de poder. En cambio, el vínculo entre Robinson y el capitán del barco inglés cuya tripulación se había amotinado contra él, es una relación de derecho, netamente contractual, en las que ambas partes reconocen la existencia de derechos y deberes mutuos sobre la base de cierta igualdad.

Una de las cimas más altas y prestigiosas del pensamiento jurídico Gustav Radbruch, caracterizado siempre por su creciente vigor didáctico, en sus obras "Introducción a la Ciencia del Derecho" e "Introducción a İa Filosofía del Derecho", hace también gala de erudición literaria, abundando en ejemplos rectores del caso jurídico; en idéntica situación están los inigualados maestros recientemente desaparecidos: Calamandrei y Couture.

No faltan, por supuesto, dentro de la didáctica jurídica ejemplos que nos revelon cómo el Juez descubre la verdad a través del proceso. En estos últimos años se presentó, en Francia, un caso que revela la astucia de un Juez en la interpretación de un contrato. Tizio demandó a Sempronio para que le pagara una suma de dinero que le adeudaba. Sempronio se presentó al Juzgado y no negó deber dicha cantidad; pero advirtió que el pacio verbal de préstamo estaba sujeto a un plazo que vencía "el día de San Blando". Para este efecto, presentó testigos, todos los que ratificaron una vez más, que Sempronio había prometido pagar a Tizio el día de San Blando. El Juez, ante la imposibilidad del cumplimiento por lo impreciso del plazo, interpretó el pacto en forma meridiana, pues, considerando que San Blando no tiene un día establecido en el calendario, sentenció que Sempronio debía hacer efectiva la prestación el .Primero de Noviembre, porque era el día de "Todos los Santos" y, por ende, día también de San Blando.

No existe, pues, escisión entre el mundo del Derecho y el de la Literatura. Por consig'uiente, el abogado no debe encontrarse en riña con ésta; todo lo contrario, debe tener presente que la abogacía es un arte y que, como tal, está fuertemente ligada con las bellas artes. Ha dicho don Angel Ossorio que "el abogado que no es orador y escritor no es abogado". Hay mucha verdad en la aseveræción. Por eso agregaremos que el hombre de Derecho no sólo debe concretarse al simple estudio de la ley, sino de la vida, que es, en su base, Filosofía y Literatura, porque sólo así estaremos verdaderamente armados por la fuerza persuasiva de lo justo. 